\title{
Com os pés na terra e a cabeça no ar
}

\author{
M A R I F I L O M N A C A M Õ E S*
}

O filósofo grego Anaximenes (500 a.C.) considerou o ar como um dos quatro elementos a partir dos quais toda a matéria seria feita, e foram necessários muitos séculos até que o cientista irlandês R. Boyle (1627-1691) o descreveu não como um elemento, mas como um material multi-elementar, "Um agregado confuso de eflúvios”.

A descoberta da composição elementar do ar atmosférico, deve-se a A. Lavoisier (1743-1794), que assim pôs fim à Teoria do Flogisto, de Sthal, marcando o princípio da era da Química e atribuindo aos dois compostos maioritários do ar os nomes por que ficaram e continuam conhecidos, Oxigénio e Azoto ou Nitrogénio. Além de Lavoisier, outros investigadores, aproximadamente na mesma altura (1777), realizaram trabalhos semelhantes.

Em 1773, os ingleses H. Cavendish (1731-1810) e J. Priestley (1733-1804) comunicaram à Royal Society, que ar que tenha atravessado carvão vegetal em combustão, vê alterada a sua natureza, sendo o Ar Residual, mais leve que o ar comum e apagando a chama de uma vela. Este Ar Queimado é tam-

* CECUL - Departamento de Química e Bioquímica, Faculdade de Ciências da Universidade de Lisboa (fcamoes@fc.ul.pt)

Apenas levou uns segundos a tirarem-Ihe a cabeça, e, talvez, um século não seja o tempo suficiente para aparecer outra cabeça como a dele (A. Lavoisier).

Joseph-Louis Lagrange, 1736-1813

bém nocivo para os animais. A justificação adiantada é a de que este $\mathbf{A r}$ Viciado estaria saturado de flogisto, sendo o Ar Flogisticado. De forma independente, D. Rutherford (1749-1819) observando propriedades análogas, defendeu na sua Tese de Doutoramento, com o título "O Ar Fixo ou Mefítico", em 12 de Novembro de 1772, fruto do seu trabalho com J. Black (1728 1799), na Universidade de Edimburgo, que 0 ar fixo, resultante da combustão de carvão, teria composição igual à do Ar Viciado ou Ar Nocivo (noxious, no termo original anglo-saxão) produzido pela respiração. 0 ar mefítico foi reportado como produzindo um precipitado por reacção com água de cal. Qualquer destes investigadores isolou componentes do ar atmosférico (oxigénio por um lado e mistura de azoto e dióxido de carbono por outro), mantendo-se no entanto adeptos da teoria do flogisto. Entretanto e apesar da evidência, $\mathrm{H}$. Davy (1778-1829) defendia que o ar era um composto e não uma mistura de compostos. O grande argumento era a densidade, pois se fossem substâncias diferentes, estariam dispostas por camadas, com a mais pesada a formar uma camada inferior e não era esse o caso, já que a Atmosfera apresentava grande homogeneidade. Cometeu o erro de não tomar em consideração o poder de mistura do vento!

Na Suécia, C. Scheele (1742-1786) que exerceu actividade de farmacêutico em Malmö, Estocolmo, Uppsala e Köping, descobriu, por volta de 1773, o Ar de Fogo (Fire Air, oxigénio), que produziu de mais que uma maneira, nomeadamente por forte aquecimento de óxido de mercúrio e óxido de manganês. Ao ar residual chamou Ar Sujo ou Ar Podre, por ser também produzido pelos corpos em putrefacção. Foi só em 1777, quando as descobertas de Priestley e de Lavoisier já eram conhecidas pela Europa, que Scheele publicou o seu livro "Tratado Químico do Ar e do Fogo" e foi só um século mais tarde, em 1892, que manuscritos de Scheele na posse da Real Academia Sueca das Ciências foram descobertos, trazendo para a luz do dia outras descobertas científicas de Scheele, designadamente de outros gases, extremamente avançadas para a época.

Também o cientista sueco T. Bergmann, (1735-1784), se referiu a um ar que é absolutamente necessário ao fogo e à vida animal, o Ar Puro, cerca de 1/4 do Ar Comum, e ao Ácido Nocivo ou Ácido Viciado que não serve para as combustões nem para a respiração, e conteria Ácido Livre (dióxido 
de carbono), em pequena quantidade, que mudava a côr da tintura de tornesol.

O cuidado posto por Lavoisier nas experiências em que usou a balança para fazer medições quantitativas sobre ar atmosférico em contacto com mercúrio aquecido, num recipiente fechado, permitiu-Ihe verificar que, ao fim de um algum tempo, 1/5 do ar disponível tinha sido consumido, transformando o mercúrio em "cal mercúrica vermelha" (óxido de mercúrio, $\mathrm{HgO}$ ). Ao ar mais leve que restava começou por chamar

\section{Gás Alcalígero ou Princípio Nitrígeno.}

As experiências de Lavoisier foram também a base da descoberta do fenómeno da respiração dos seres vivos. Ratos colocados dentro do recipiente da experiência, inspirando-o, morriam e, uma vela acesa, posta em contacto com esse ar, apagava-se. Concluiu que o mercúrio tinha absorvido a parte respirável do ar, a que chamou Oxigénio, (do grego oxys + gignomai, que significa "gerador de ácidos", pois pensou que todos os ácidos continham oxigénio (Apesar de a conclusão, por precipitada, estar errada, esta descoberta representa a primeira associação do comportamento dos "ácidos" com a sua composição química). A contra-prova foi feita aquecendo a cal mercúrica, recolhendo o gás libertado, respirável, e juntando-o à porção de ar irrespirável para obter de novo ar normal. Aos 4/5 residuais do ar atmosférico, gás passivo que entra nos pulmões e dele sai sem sofrer alterações, Lavoisier chamou Mofeta ${ }^{1}$ (ou Mofeta Residual). Sendo impróprio para a respiração, e por sugestão do seu amigo e colaborador Guyton de Morveau, chamou-Ihe Azoe, Gas Azotique, ou Azote, com símbolo $\mathbf{A z}$, palavra de origem grega (do grego $a+z 00$, que significa "sem vida"), nome pelo qual é conhecido em França e nos países de cultura francófona. Curiosamente, sabe-se hoje que a composição média nos organismos vivos é de 16\% em Azoto, fundamen- talmente na constituição das proteínas, enquanto que a sua abundância global é de $0,3 \%$.

Noutra experiência, Lavoisier colocou um pássaro num recipiente com ar atmosférico; ao fim de alguns minutos o pássaro morreu. 0 ar residual não continha gás respirável, mas tinha adquirido a propriedade de turvar a água de cal; teria portanto Ácido Cretoso Aeriforme (anidrido carbónico ou dióxido de carbono, $\mathrm{CO}_{2}$ ). Para reconstituir o ar atmosférico normal, haveria que retirar o dióxido de carbono e adicionar oxigénio em quantidade igual à perdida.

$\mathrm{O}$ nome Nitrogène, com o símbolo $\mathbf{N}$, (do latim nitru, e do grego nitron + gignomai no sentido de produtor de "nitro", ou "salitre" substância essencial para o fabrico da pólvora), foi proposto, 1790, por Juan Antonio Chaptal, responsável pelo fabrico da pólvora para os exércitos revolucionários franceses. No mesmo ano, Antonio Porcel propôs o nome Nitrígeno baseado na sua presença no ácido nítrico (ou azótico) e posteriormente Amoniágeno, por formar amoníaco. A designação que se propagou internacionalmente foi, de forma geral, a de "Nitrogène" com as correspondentes traduções em várias línguas. Em algumas, poucas, línguas permaneceu o original "Azote" ou as traduções como o mesmo significado intrínseco, ou são usadas ambas: Inglês e Irlandês: Nitrogen; Português- Azoto e Nitrogénio; Espanhol: Azoe, Gas Azoe ou Gas Azotique e Nitrógeno; Grego: Azoton; Italiano: Azoto; Alemão: Stick Stoff (que sufoca+ matéria de ar que não serve para a respiração); Holandês: Stikstof; Japonês: Chin Su ou Tan Ch'i (Gás Irrespirável) e Hsiao Ch'i; Polaco: Dušik (Irrespirável); Russo: Azot; Servocroata- Dusik.

No final do século XVIII estavam identificados os gases maioritários, Azoto ou Nitrogénio, $\mathbf{N}_{\mathbf{2}},(78 \%)$, Oxigénio, $\mathbf{O}_{\mathbf{2}}$, (21\%) e Anidrido Carbónico, $\mathbf{C O}_{\mathbf{2}}$, $(0,035 \%)$ e outros gases minoritários, de menor estabilidade química e tempo de residência, tais como amoníaco e óxidos de azoto e de enxofre (ÁRGON, do grego argon, inativo, constituindo aproximadamente 0,9\% do ar, foi descoberto em 1894 pelos ingleses W. Ramsey e W. Rayleigh).

O ar atmosférico foi o grande veículo para o desenvolvimento das primeiras leis químicas, período que se iniciou com a Lei da Conservação da Massa de Lavoisier "Nada se perde, nada se ganha, tudo se transforma" e se propagou pelo século XIX. Posteriormente, na 1. a metade do século XX o interesse centrou-se na Química e na Física da Alta Atmosfera, com importantes descobertas no domínio da aeronáutica e das ciências aeroespaciais. A 2. ${ }^{a}$ metade viu o renovar do interesse nas propriedades das camadas inferiores da Atmosfera, na origem da moderna área científica da Química Atmosférica, evidenciando a importância dos gases vestigiais, dos aerossóis e da precipitação húmida, e que é hoje um dos focos do interesse público dada a sua interface entre a Química e as Ciências do Ambiente, importante Metaciência ${ }^{2}$ da actualidade. (Beyond Classical Chemistry - Subfields and Metafields of the Molecular Sciences).

Notas

[1] Mofeta: nome vulgar de mamífero carnívoro (doninha) de cerca de $40 \mathrm{~cm}$ de comprimento, mais $20 \mathrm{~cm}$ de cauda, de cabeça pequena e focinho pontiagudo, de patas curtas, pêlo comprido e eriçado de cor parda com uma faixa branca ao longo da cauda e que se caracteriza por ter umas glândulas que, como defesa, produzem um cheiro fétido.

[2] Para mais detalhes consultar o artigo "Beyond Classical Chemistry - Subfields and Metafields of the Molecular Sciences", J. Sjöström, Chemistry International, $\mathbf{2 8}$ (2006) 9-15. 